\title{
Using fuzzy logic to generate conditional probabilities in Bayesian belief networks: a case study of ecological assessment
}

\author{
K. F.-R. Liu • J.-Y. Kuo $\cdot$ K. Yeh $\cdot$ C.-W. Chen • \\ H.-H. Liang $\cdot$ Y.-H. Sun
}

Received: 15 November 2012/Revised: 15 June 2013/Accepted: 24 November 2013/Published online: 17 December 2013

(C) Islamic Azad University (IAU) 2013

\begin{abstract}
The survival of rare animals is an important concern in an environmental impact assessment. However, it is very difficult to quantitatively predict the possible effect that a development project has on rare animals, and there is a heavy reliance on expert knowledge and judgment. In order to improve the credibility of expert judgment, this study uses Bayesian belief networks (BBN) to
\end{abstract}

Electronic supplementary material The online version of this article (doi:10.1007/s13762-013-0459-x) contains supplementary material, which is available to authorized users.

K. F.-R. Liu ( $\square)$

Department of Safety, Health and Environmental Engineering,

Ming Chi University of Technology, New Taipei 24301,

Taiwan, ROC

e-mail: kevinliu@mail.mcut.edu.tw

J.-Y. Kuo

Department of Computer Science and Information Engineering, National Taipei University of Technology, Taipei 10608,

Taiwan, ROC

K. Yeh

Department of Construction Science and Technology, De-Lin Institute of Technology, New Taipei 23654, Taiwan, ROC

C.-W. Chen

Institute of Maritime Information and Technology, National

Kaohsiung Marine University, Kaohsiung 80543, Taiwan, ROC

H.-H. Liang

Department of Architecture, National United University,

Miaoli 36003, Taiwan, ROC

Y.-H. Sun

Institute of Wildlife Conservation, National Pingtung University of Science and Technology, Pingtung 91201, Taiwan, ROC visually represent expert knowledge and to clearly explain the inference process. For the case study, the primary difficulty is in determining a large amount of conditional probabilities in the BBN, because there is a lack of sufficient data concerning rare animals. Therefore, a new method that uses fuzzy logic to systematically generate these probabilities is proposed. The combination of the BBN and the fuzzy logic system is used to assess the possible future population status of the Pheasant-tailed jacana and the associated probabilities, which have been affected by the construction of the Taiwan High-Speed Rail. The analysis shows that a restoration program would successfully preserve the species, because in the restoration area, the BBN model predicts that there is a $75.49 \%$ probability that the species will flourish in the future.

Keywords Pheasant-tailed jacana $\cdot$ Future population status · Expert judgment $\cdot$ Artificial intelligence

\section{Introduction}

Environmental impact assessment (EIA) is a procedural tool which involves the processes of identification, prediction, evaluation, and mitigation of the biophysical, social, and other relevant effects of development projects, before major decisions and commitments are made (Petts 1999). Development projects for which there is a possibility of adverse impact on the environment must submit an environmental impact assessment report (EIAR), and this EIAR must then be forwarded to competent authorities for review. A development project is refused if its adverse impact is significant. Usually, the survival of rare animals is an important criterion in determining whether the impact of a development project is significant. A study of the 34 
EIARs for road construction in Taiwan over the past 5 years (2007-2011) shows that, in practice, the tools that are usually used to estimate the degree of the impact on protected or rare animals mostly rely heavily on expert knowledge and judgment, alone, and make limited use of empirical data. Despite the continued advances in empirical or statistical methods for complex and dynamic ecosystems, most EIARs still use expert opinion, when assessing the impact on rare animals. One possible reason for this is that there is difficulty in obtaining sufficient scientific information that enables the complicated causeand-effect relationships between a variety of stressors (external intervention and change in the physical, chemical, biological, and natural environment) and a receptor (a specific rare animal) to be identified, so changes made by man that affect rare animals cannot be adequately quantified, but experts can qualitatively forecast the possible consequences for rare animals that result from development projects. Aside from its use in forecasting the impact on rare animals, expert judgment is widely used in biological conservation, partially because of the complexity of the problems encountered, the relative lack of data, and the imminent nature of many conservation decisions (Martin et al. 2012).

Although expert judgment can be used to assess the impact on rare animals, in an EIS, it is usually criticized, because decisions are made in isolation, based on intuition or conjecture, so the reason for the judgment is not often readily explicable. In order to address this concern, methods that can explicitly express expert knowledge and clearly explain the process of inference are required. A total of 36 studies, which are described in the next paragraph, have demonstrated the utility of BBNs (Pearl 1988) in garnering and integrating expert knowledge and empirical data concerning ecological issues. The $\mathrm{BBN}$ is a directed acyclic graph with nodes, which denotes a set of random variables as nodes and arrows. These indicate the probabilistic cause-and-effect dependencies. A number of properties make it particularly useful for ecological applications; it allows the use of a combination of qualitative knowledge and quantitative data (Aguilera et al. 2011), so it can easily cope with missing data and it can be constructed using observed data, other models, or expert knowledge. It is a useful tool for risk assessment, because it explicitly incorporates uncertainty in relationships. It is also useful in ecological risk management, because the effects are identified, given the causes, or the causes, given the effects (Hart and Pollino 2008).

The number of studies concerning the application of the BBN for ecological issues has dramatically increased, in recent years. A total of 36 relevant papers have been published and most of these (28 out of 36) were published after 2006. This demonstrates the potential of BBN for use in ecological issues. The BBN has been used for a variety of predictions, assessments, and characterizations of ecological issues, such as population health, or the future status of fish stocks (Rieman et al. 2001; Borsuk et al. 2003, 2004, 2006; Pollino et al. 2007a; Shenton et al. 2011; Nicholson and Flores 2011; Vilizzi et al. 2012; Chan et al. 2012), amphibians (Wilson et al. 2008), small passerines (Howes et al. 2010), endangered Eucalyptus camphora (Pollino et al. 2007b), terrestrial lichens (Nyberg et al. 2006), the prediction of the spatial distribution of species (Walton and Meidinger 2006; Aguilera et al. 2011; Grech and Coles 2010; Dlamini 2011), the viability of populations of at-risk species (Marcot et al. 2001; Steventon et al. 2006), fish production capacity (Hammond and Ellis 2002; Uusitalo et al. 2005), the success of cheetah relocation (Johnson et al. 2010), net ecosystem metabolism in an estuary (Young et al. 2011), large-scale coral bleaching (Wooldridge and Done 2004), reef condition (Shenton et al. 2010), the prediction of the coverage of coral reef macroalgae (Renken and Mumby 2009), bloom initiation for Lyngbya majuscula (Hamilton et al. 2007), habitat conditions (Raphael et al. 2001; Sadoddin et al. 2005; McNay et al. 2006; Smith et al. 2007) and in combination with management strategies (Marcot et al. 2006; Gibbs 2007; Bashari et al. 2008; Newton 2010; Helle et al. 2011). Table 1 shows five characteristics (and their options), as detailed in the review paper by Aguilera et al. (2011). These are used to analyze the 36 papers in terms of variables (discrete, continuous, both), model learning (data/ simulation, experts/literature, both), and evaluation (train

Table 1 Distribution of five characteristics over the options for the 36 papers analyzed

\begin{tabular}{llrr}
\hline Characteristic & Options & Total & $\%$ \\
\hline Variable & Discrete & 33 & 91.6 \\
& Continuous & 2 & 5.6 \\
& Both & 1 & 2.8 \\
Establishment of BBN structure & Experts/literature & 26 & 78.8 \\
& Data/simulation & 3 & 8.38 \\
& Not available & 7 & 19.4 \\
Generation of CP & Experts/literature & 20 & 55.5 \\
& Data/simulation & 10 & 27.8 \\
Software & Both & 6 & 16.7 \\
& Netica & 16 & 44.4 \\
Evaluation & Hugin & 4 & 11.2 \\
& Others & 16 & 44.4 \\
& Sensitivity analysis & 15 & 41.6 \\
& Train and test & 4 & 11.1 \\
& Hybrid & 6 & 16.7 \\
& Cross validation & 1 & 2.8 \\
& Not available & 10 & 27.8 \\
\hline
\end{tabular}


and test, sensitivity analysis, hybrid, cross validation, not available).

Usually, the values for each node in the BBN are categorized into a finite number of levels. The greater the number of levels, the more complex and precise is the model, but the greater is the amount of data required to construct conditional probabilities (CPs). In practice, 2-10 levels are usually used in ecological studies (Uusitalo 2007). In this research, five levels are used, producing $19,625 \mathrm{CPs}$ in the BBN model of the case study. However, it is extremely difficult to obtain sufficient data (whether field data or expert survey) for the rare animal, the Pheasant-tailed jacana, to construct these CPs, so subjective judgment is used. This is also known as an expertdriven BBN (Oteniya 2008; Radliński 2013). Similarly, $55.5 \%$ of the related papers (Table 1) use expert opinion or literature to populate the CPs, in the cases where very little empirical data are available, but none detail how the expertise is converted into CPs.

The expert-driven methods used to generate CPs can be approximately classified into three groups: the direct assignment method, the weighted sum algorithm, and fuzzy fault tree (FFT) analysis. The first group of researchers used the direct assignment method because the number of the CPs was small and the experts could easily estimate the CPs. While the subjective estimations for the CPs are usually expressed linguistically, several studies ( $\mathrm{Li}$ and Kao 2005; Ren et al. 2009; Kao et al. 2011; Li et al. 2012) extend the concept of a conventional BBN to allow fuzzy probabilities (fuzzy BBN). The second group of researchers (Das 2004; Baker and Mendes 2010) devised the weighted sum algorithm, which means that experts estimate less CPs, but they must additionally assess the relative strengths (weights) of the influences of the parentnodes on a child-node. The third group of researchers (Wang et al. 2011; Wang and Xie 2012) mapped FFT into BBNs. In the FFT method, experts directly assign the probabilities in the rules of Takagi and Sugeno model, which represent the uncertain relationships among different events, so these are the CPs in the BBN. The direct assignment method, the weighted sum algorithm, or FFT analysis are not suitable for this study, because of the large amount of CPs $(19,625)$ in the case study. Therefore, a new expert-driven method to generate a large amount of CPs is proposed, which employs fuzzy logic (Zadeh 1996, 2002) to construct less heuristic rules elicited from experts and to automatically infer more CPs, using these rules.

The use of BBN or fuzzy logic in environmental science and technology is common, as seen in the studies of Liu et al. (2012, 2013), Tuzkaya and Gulsun (2008), Tuzkaya et al. (2009), Karimi et al. (2011), Bangian et al. (2012) and Tuzkaya (2013), but the combination of fuzzy logic and $\mathrm{BBN}$ in this field or in ecology is not quite seen in literatures. In this study, fuzzy logic is integrated into the $\mathrm{BBN}$ model as an ecological assessment tool for EIA. Finally, the assessment of the future population status of the Pheasant-tailed jacana due to the construction of the Taiwan High-Speed Rail (THSR) is used as a case study, in order to demonstrate the use of the method. This research was undertaken by the Department of Safety, Health and Environmental Engineering, Ming Chi University of Technology (Taipei; Taiwan), from August 2011 to July 2012.

\section{Materials and methods}

\section{Case study}

The rugged central mountainous terrain of Taiwan has hindered the population and socio-economical growth, so economic activity has mainly developed along the plains of the West Coast. The increasing demands for north-south intercity transportation led to the birth of the THSR system. In 1987, because of the deteriorating quality and saturation of the transportation system in the Western Corridor, the Executive Yuan commissioned the Taiwanese Transportation Bureau to undertake a feasibility study for a HighSpeed Rail System in the Western Corridor. The aim of this study was to improve the transportation service in this area and to coordinate with the metropolitan rapid transport system plan for the construction of a complete transportation network. After almost 13 years of preparation and planning, the construction work for the THSR system began on March 27, 2000. The THSR project, the route of which is mapped in Fig. 1, is not only one of the most challenging infrastructure projects in the world, to date, but also boasts the largest private sector investment in a public construction project. The total investment needed for construction was approximately USD 18 billion. The planned system was $344.68 \mathrm{~km}$ in length, including $252 \mathrm{~km}$ of overpasses and $48 \mathrm{~km}$ of tunnels and revenue service commenced in 2006. The THSR line runs from Taipei to Kaohsiung, passing 14 major cities and counties and 77 townships and regions, including Guantian. Guantian is an agricultural town in Tainan County, well known for its water caltrop farms and produce. Due to the abundance of water caltrop farms and other water-based vegetation farms, Guantian is also an important habitat for many species of water birds especially the rare Pheasant-tailed jacana. 


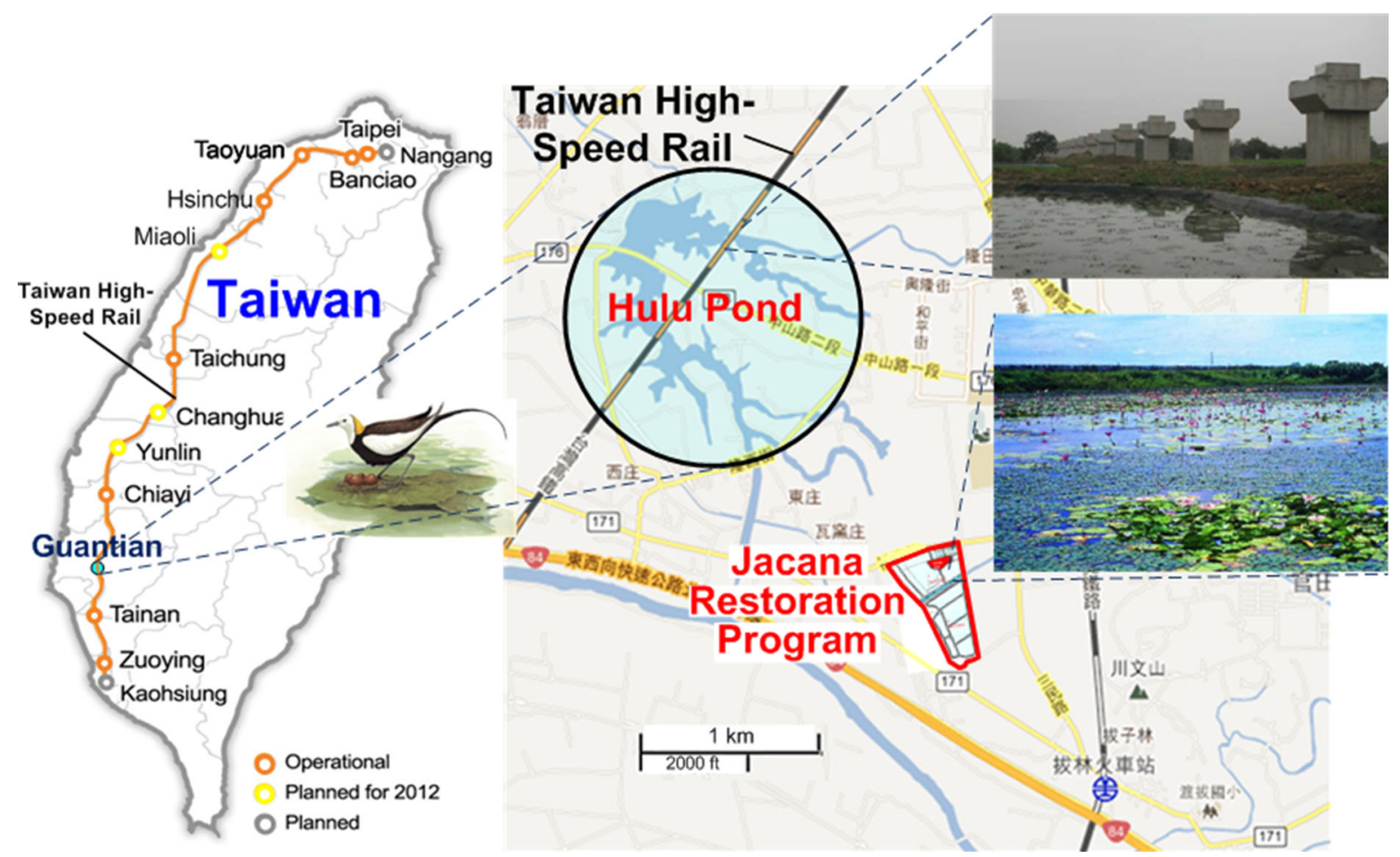

Fig. 1 The major habitat of the Pheasant-tailed jacanas, Hulu pond, and its disturbance by the construction of the THSR

The Pheasant-tailed jacanas are found in Southern China, the Philippines, and the Middle of the Southern Peninsula, as well as in Taiwan. The rear of the jacana's neck is golden in color and its feathers are dazzling. The males take on the responsibility for the incubation of the eggs and the care of the hatchlings. The jacana is a conspicuous and unmistakable bird that builds its nest on the water caltrops, lotus leaves, and other floating vegetation, in order to prevent attack from land predators. In accordance with the studies by Deng (2002, 2010), Chen (2008), Chiu (2004) and Ueng (2008), several essential survival factors influencing the future population status of the Pheasant-tailed jacana are shown in Fig. 2. Brushwood and shrubbery provide a buffer against enemies; swampland is a place for nesting; embankments prevent disturbance to breeding and also provide shelter from cold winds; water caltrop is an important place for nesting, foraging, and resting; mud is essential for winter foraging; rice is the secondary food source; water quality influences survival; and finally, exterior threats from human disturbance or predators also affect the future population status. These factors determine the suitability of breeding environment, hibernacula surrounding, foraging condition, and habitat (see Fig. 2).
Pheasant-tailed jacanas used to be quite a common sight on farmlands in Taiwan. However, the development of freeways through different ponds, farmland, and other water caltrop production regions has caused a decrease in wetland habitats and has resulted in a severe reduction in their numbers. Today, the Pheasant-tailed jacana is one of the most endangered bird species in the world. Therefore, the number of the Pheasant-tailed jacana is an indicator of the success of any complete fully functioning wetland ecosystem where the Pheasant-tailed jacana is to be found. Unfortunately, the THSR was built across the most important habitat for the Pheasant-tailed jacana, Hulu pond, and many water caltrop farms and jacana's natural habitat were disturbed, as shown in Fig. 2.

In this study, four scenarios for the future population status of the Pheasant-tailed jacanas are discussed in the EIA report. The first scenario is the baseline condition (BC). Hulu pond is the largest, stable habitat for the jacana because it contains a large amount of water chestnut. However, in winter, water chestnut wilt and no floating leaves are available, so the jacana must live in ditches, abandoned fishponds, or riverbanks, leading to their predation by dogs or other animals. Suitable ponds for the jacana usually have deep embankments, but in the Hulu pond many embankments are 


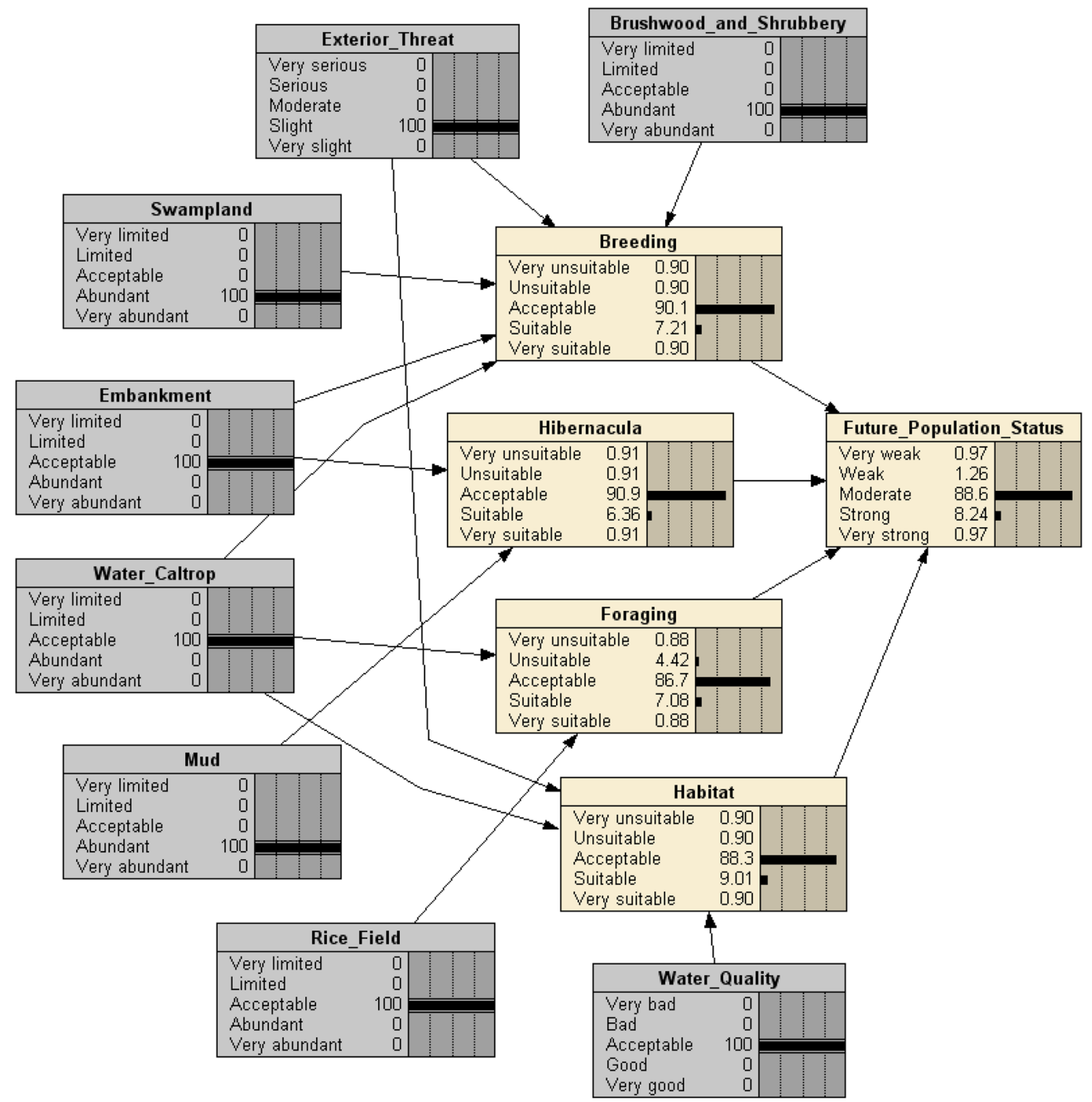

Fig. 2 Essential survival factors influencing the future population status of the Pheasant-tailed jacana (shown by the BBN model)

shallow, which causes a lack of shelter and allows interference from the outside. In addition, illegal industrial wastewater from the nearby Kuantien Industrial Park has been discharged into the pond, leading to eutrophication in the pond, and the excessive use of pesticides in the surrounding agricultural areas has polluted the water. The second scenario is the prediction of the impact without mitigation measures (PIWOM). During the construction of the THSR, personnel, vehicles, and construction equipment cause noise, vibration, and pollution, which seriously affects the breeding, foraging, habitat, and hibernacula of the jacana. The third scenario is the prediction of the impact with mitigation measures (PIWM). The mitigation measures include reducing the scale of construction in the area, using low-noise construction equipment/technology and avoiding building piers in the pond. Waste soil and wastewater are also prevented from being discharged into the pond, to avoid pollution of the water. The construction period should also take account of the ecology of the jacana, and construction should be avoided from October to April. The fourth scenario is the prediction of the impact with a restoration program (RP). Tainan County and THSR reserved a district approximately $2 \mathrm{~km}$ away from Hulu pond, to create a habitat in which the jacanas can live and breed. This land was chosen because it is a potential wetland close to breeding populations (Hulu pond) and is an easily accessible water resource (Chi-Nan irrigation system). The land is divided into two parts of 7 and 8 hectares on each side by Chi-Nan irrigation system. The 7-hectare area to the north includes a large pool, two small ponds, and a nursery pond. There are another four large 
ponds in the 8-hectare area to the south. Water chestnuts will be planted in the early phase, and more aquatic plants will be added in the future. Winter is usually dry and the water supply is scarce in southern Taiwan, but because the ponds to the south are deeper they are able to retain enough water to ensure the survival of animals. In winter, when water chestnuts die, other than putting in man-made islands, fragrant lilies and aquatic plants that grow in the winter will be

Table 2 The detailed information for the four scenarios

\begin{tabular}{|c|c|c|c|c|}
\hline Scenario & $\mathrm{BC}$ & PIWOM & PIWM & $\mathrm{RP}$ \\
\hline $\begin{array}{l}\text { Brushwood } \\
\text { and } \\
\text { shrubbery }\end{array}$ & Abundant & Acceptable & Acceptable & $\begin{array}{l}\text { Very } \\
\text { abundant }\end{array}$ \\
\hline Exterior threat & Slight & Serious & Moderate & Slight \\
\hline Swampland & Abundant & Limited & Acceptable & Abundant \\
\hline Embankment & Acceptable & Limited & Limited & Abundant \\
\hline Water caltrop & Acceptable & Limited & Acceptable & $\begin{array}{l}\text { Very } \\
\text { abundant }\end{array}$ \\
\hline Mud & Abundant & Limited & Acceptable & $\begin{array}{l}\text { Very } \\
\text { abundant }\end{array}$ \\
\hline Rice field & Acceptable & Acceptable & Acceptable & Acceptable \\
\hline Water quality & Acceptable & $\mathrm{Bad}$ & Acceptable & $\begin{array}{l}\text { Very } \\
\text { abundant }\end{array}$ \\
\hline
\end{tabular}

planted in the ponds, to make them more habitable for the jacanas in winter. The detailed information for the four scenarios is shown in Table 2.

Bayesian belief network

A BBN is a directed acyclic graph wherein the nodes represent random variables $\left(X_{\mathrm{i}}\right)$ that have several possible states and the arrows connect pairs of nodes and show their probabilistic cause-and-effect relationships. Each node with parents is associated with a conditional probability table that contains many CPs and quantifies the uncertain effects that the parents have on the node; those nodes without a parent have a probability distribution over all possible states. These probabilities are evaluated using historical data, expert judgment, or a combination of both, as shown in Table 1. $\mathrm{A} \mathrm{BBN}$ has an associated computational structure, so it can calculate the bi-directional propagations of beliefs between nodes and ultimately determine a probability distribution over all possible states for each node, for a given set of evidence. This feature can be used to test scenarios, under either data-driven or goal-driven circumstances.

There are three important elements in the development of a BBN (Liu et al. 2012): nodes (key factors), networks

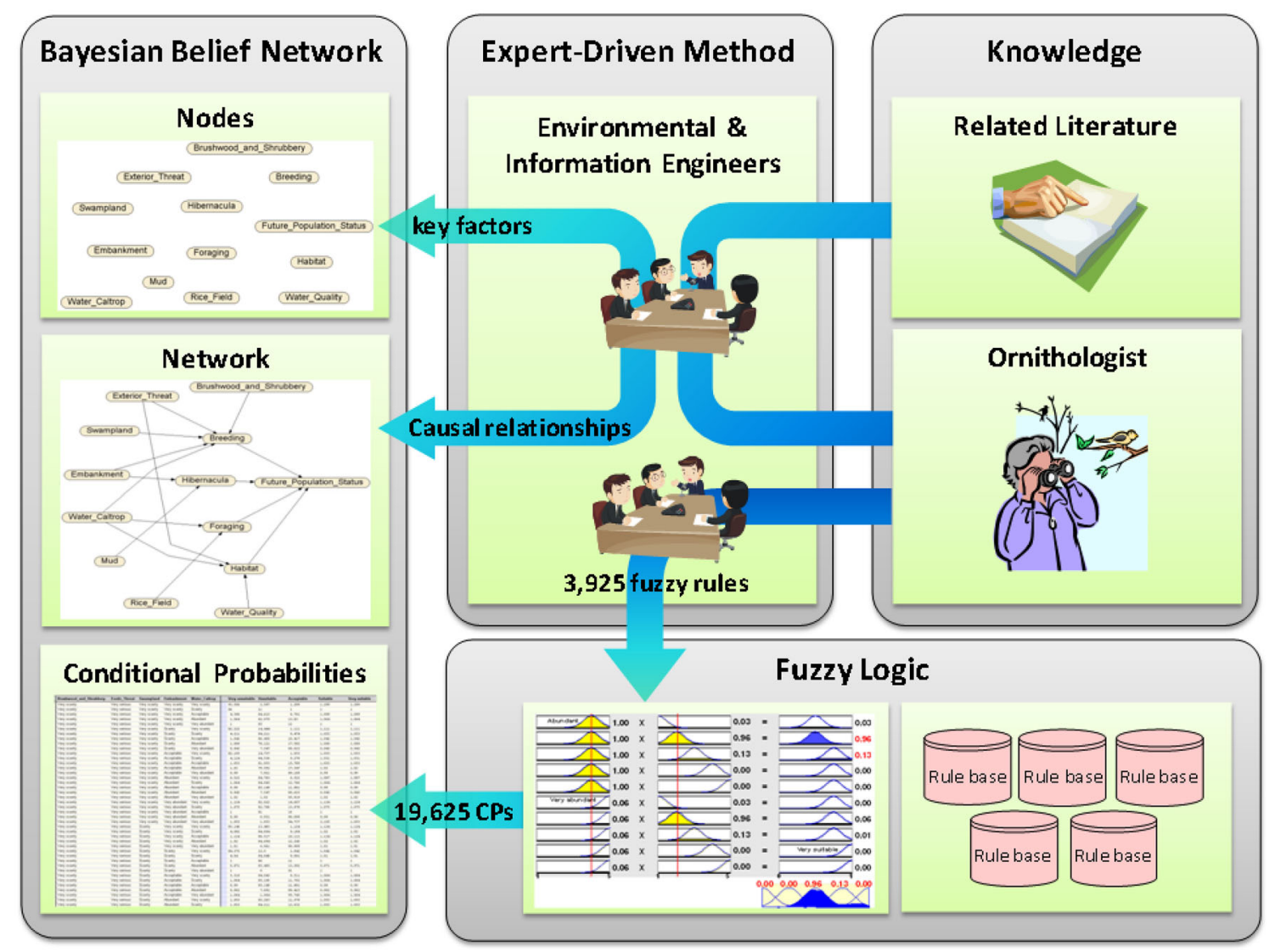

Fig. 3 The development procedure for an expert-driven BBN using fuzzy logic 
Table 3 The 125 conditional probabilities for the suitability of the foraging environment

\begin{tabular}{|c|c|c|c|c|c|c|c|}
\hline \multirow[t]{2}{*}{ No } & \multirow[t]{2}{*}{ Water caltrop $(1-5)$} & \multirow[t]{2}{*}{ Rice field (1-5) } & \multicolumn{5}{|l|}{ Foraging $(\%)$} \\
\hline & & & Very unsuitable & Unsuitable & Acceptable & Suitable & Very suitable \\
\hline 1 & Very limited & Very limited & 86.7 & 10.5 & 1.0 & 1.0 & 1.0 \\
\hline 2 & Very limited & Limited & 83.3 & 13.9 & 0.9 & 0.9 & 0.9 \\
\hline 3 & Very limited & Acceptable & 5.1 & 90.9 & 2.0 & 1.0 & 1.0 \\
\hline 4 & Very limited & Abundant & 0.9 & 86.5 & 10.8 & 0.9 & 0.9 \\
\hline 5 & Very limited & Very abundant & 0.9 & 84.5 & 12.7 & 0.9 & 0.9 \\
\hline 6 & Limited & Very limited & 4.1 & 91.8 & 2.1 & 1.0 & 1.0 \\
\hline 7 & Limited & Limited & 3.7 & 85.2 & 9.3 & 0.9 & 0.9 \\
\hline 8 & Limited & Acceptable & 0.9 & 88.1 & 9.2 & 0.9 & 0.9 \\
\hline 9 & Limited & Abundant & 0.9 & 6.5 & 90.7 & 0.9 & 0.9 \\
\hline 10 & Limited & Very abundant & 0.9 & 3.5 & 84.3 & 10.4 & 0.9 \\
\hline 11 & Acceptable & Very limited & 0.9 & 86.5 & 10.8 & 0.9 & 0.9 \\
\hline 12 & Acceptable & Limited & 1.0 & 5.7 & 91.4 & 1.0 & 1.0 \\
\hline 13 & Acceptable & Acceptable & 0.9 & 4.4 & 86.7 & 7.1 & 0.9 \\
\hline 14 & Acceptable & Abundant & 0.9 & 0.9 & 90.1 & 7.2 & 0.9 \\
\hline 15 & Acceptable & Very abundant & 0.9 & 0.9 & 9.2 & 88.1 & 0.9 \\
\hline 16 & Abundant & Very limited & 0.9 & 6.6 & 86.8 & 4.7 & 0.9 \\
\hline 17 & Abundant (3.988) & Limited (2.126) & 0.9 & 0.9 & 85.7 & 11.6 & 0.9 \\
\hline 18 & Abundant & Acceptable & 0.9 & 0.9 & 7.2 & 90.1 & 0.9 \\
\hline 19 & Abundant & Abundant & 0.9 & 0.9 & 6.9 & 86.2 & 5.2 \\
\hline 20 & Abundant & Very abundant & 0.9 & 0.9 & 0.9 & 91.7 & 5.5 \\
\hline 21 & Very abundant & Very limited & 1.0 & 1.0 & 7.8 & 89.2 & 1.0 \\
\hline 22 & Very abundant & Limited & 0.9 & 0.9 & 6.4 & 90.9 & 0.9 \\
\hline 23 & Very abundant & Acceptable & 0.9 & 0.9 & 0.9 & 89.1 & 8.2 \\
\hline 24 & Very abundant & Abundant & 0.9 & 0.9 & 0.9 & 8.1 & 89.2 \\
\hline 25 & Very abundant & Very abundant & 0.9 & 0.9 & 0.9 & 6.4 & 90.9 \\
\hline
\end{tabular}

(causal relationships), and CPs (uncertainty causal relationships). For the assessment of rare animals, there is no relevant information, so these three elements are established by means of an expert panel. The expert panel consists of the authors: an ornithologist and several specialists in environmental management or information systems, who formulate the BBN model according to the guidelines proposed by Marcot et al. (2006), as shown in Fig. 3. Firstly, the experts identify the key factors affecting the Pheasant-tailed jacana, as detailed by related literature, to create influence diagrams and develop an initial, tentative BBN model. The tentative BBN model is then revised following an interview with the ornithologist. The fuzzy logic system is then designed by the expert panel and the associated 3,925 fuzzy rules are extracted from the information provided by the ornithologist. The 19,625 CPs are determined using the fuzzy logic system. An iterative process is then used to calibrate the fuzzy rules, before a final workable set of CPs is produced, which creates the final BBN model.
The use of fuzzy logic to generate CPs

It is very difficult for experts to evaluate the $19,625 \mathrm{CPs}$; therefore, fuzzy logic is used to help the experts. For example, the suitability of the foraging environment is determined by the conditions of the water caltrop and rice fields; the 125 CPs are shown in Table 3. The five CPs in row no. 17 of Table $3, \mathrm{P}=$ (Foraging $=$ lwater caltrop $=$ abundant and rice field $=$ limited), demonstrate the derivation of the fuzzy logic.

Fuzzy logic (Zadeh 1996, 2002) is a tool with the ability to compute with words for the analysis of complex systems and decisions, in order to model qualitative human thought processes. Fuzzy logic represents qualitative perceptionbased reasoning by "IF-THEN" fuzzy rules, which makes it easier for experts to express their judgment of CPs. In the suitability of foraging example, the evaluation rules for generating the associated CPs are easily seen in Table 4, where "water caltrop," "rice field," and "the suitability of 
Table 4 Fuzzy rules for generating the CPs of foraging environment

\begin{tabular}{|c|c|c|c|}
\hline \multirow[t]{2}{*}{ Rule No } & \multicolumn{2}{|l|}{ IF part } & \multirow{2}{*}{$\begin{array}{l}\text { THEN part } \\
\text { Foraging }\end{array}$} \\
\hline & Water caltrop & Rice Field & \\
\hline 1 & Very limited & Very limited & Very unsuitable \\
\hline 2 & Very limited & Limited & Very unsuitable \\
\hline 3 & Very limited & Acceptable & Unsuitable \\
\hline 4 & Very limited & Abundant & Unsuitable \\
\hline 5 & Very limited & Very abundant & Unsuitable \\
\hline 6 & Limited & Very limited & Unsuitable \\
\hline 7 & Limited & Limited & Unsuitable \\
\hline 8 & Limited & Acceptable & Unsuitable \\
\hline 9 & Limited & Abundant & Acceptable \\
\hline 10 & Limited & Very abundant & Acceptable \\
\hline 11 & Acceptable & Very limited & Unsuitable \\
\hline 12 & Acceptable & Limited & Acceptable \\
\hline 13 & Acceptable & Acceptable & Acceptable \\
\hline 14 & Acceptable & Abundant & Acceptable \\
\hline 15 & Acceptable & Very abundant & Suitable \\
\hline 16 & Abundant & Very limited & Acceptable \\
\hline 17 & Abundant & Limited & Acceptable \\
\hline 18 & Abundant & Acceptable & Suitable \\
\hline 19 & Abundant & Abundant & Suitable \\
\hline 20 & Abundant & Very abundant & Suitable \\
\hline 21 & Very abundant & Very limited & Suitable \\
\hline 22 & Very abundant & Limited & Suitable \\
\hline 23 & Very abundant & Acceptable & Suitable \\
\hline 24 & Very abundant & Abundant & Very suitable \\
\hline 25 & Very abundant & Very abundant & Very suitable \\
\hline
\end{tabular}

foraging" are linguistic variables (Zadeh 1975) and "very limited," "limited," “acceptable," “abundant," "very abundant," "very unsuitable," "unsuitable," "acceptable," "suitable," and "very suitable" are the possible fuzzy values, which are defined by Gaussian distribution, as shown in Fig. 4. Instead of widely used triangular membership functions, the Gaussian distribution is used herein because a study (Mandal et al. 2012) has made a comparison among the predicted data using different membership functions and it indicated that the Gaussian distribution has less error in prediction of data than the triangular one.

In order to account for any bias due to subjective judgment, the values for "water caltrop = abundant" and "rice field = limited" are randomly selected around the peak of the Gaussian distributions; they are 3.988 and 2.126 , respectively. The two values are fed into this inference mechanism and fuzzy logic proceeds. Fuzzy logic is easily explained using a graphical representation, as shown in Fig. 4. This figure shows the three major steps involved in inferring a conclusion, using fuzzy reasoning (Liu and Lai 2009): computing compatibility, truncating conclusions, and aggregating truncated conclusions. The first step defines compatibility as the similarity of an antecedent, which refers to a fact having the same linguistic variable, or the suitability of a specific rule with regard to several facts, as its respective antecedents. For Rule 13, the compatibility of "water caltrop = abundant" with "water caltrop $=$ acceptable" is 0.07 , and for "rice field = limited," its compatibility with "rice field $=$ acceptable" is 0.13 , so the overall compatibility of Rule 13 with the four facts is $0.07 \times 0.13$, which is 0.01 . It should be noted that "algebraic product" is chosen as the $\mathrm{t}$-norm operator, rather than using another more widely used t-norm operator, "min," because the t-norm operator, "product," makes the conclusion sensitive to every input, whereas only one input controls the conclusion in the case of the t-norm operator, "min." The compatibility of other rules is calculated in the same way. The second step computes the degree to which the antecedents are satisfied by each rule. As shown in Fig. 4, a new conclusion is then inferred, by truncating the Gaussian conclusion of each rule with its corresponding compatibility. The last step aggregates several inferred conclusions with the same linguistic variable. Aggregation is the process by which the fuzzy sets representing the truncated conclusions of triggered rules are combined into a single fuzzy set. In Fig. 4, the final conclusion is aggregated by taking the union of all truncated conclusions. Ultimately, the conditional possibilities for "the suitability of foraging = very unsuitable," "foraging = unsuitable," "foraging = acceptable," "foraging $=$ suitable," and "foraging $=$ very suitable" are $0.00,0.00,0.96,0.13,0.00$, respectively. However, the lowest possibility, 0.01 , is tolerated in the situation where the possibility is zero because every state of the suitability of foraging is possible and its possibility should be greater than zero. Therefore, these conditional possibilities are further edited, as follows, and their summation is 1.12.

Poss(Foraging $=$ very unsuitable $\mid$ water caltrop $=$ abundant and rice field $=$ limited)

$=0.01$

Poss(Foraging $=$ unsuitable I water caltrop $=$ abundant and rice field $=$ limited)

$=0.01$

Poss $($ Foraging $=$ acceptable I water caltrop $=$ abundant and rice field $=$ limited)

$=0.96$

Poss $($ Foraging $=$ suitable $\quad$ water caltrop $=$ abundant and rice field $=$ limited)

$=0.13$ 
Fig. 4 Graphical representation of fuzzy logic

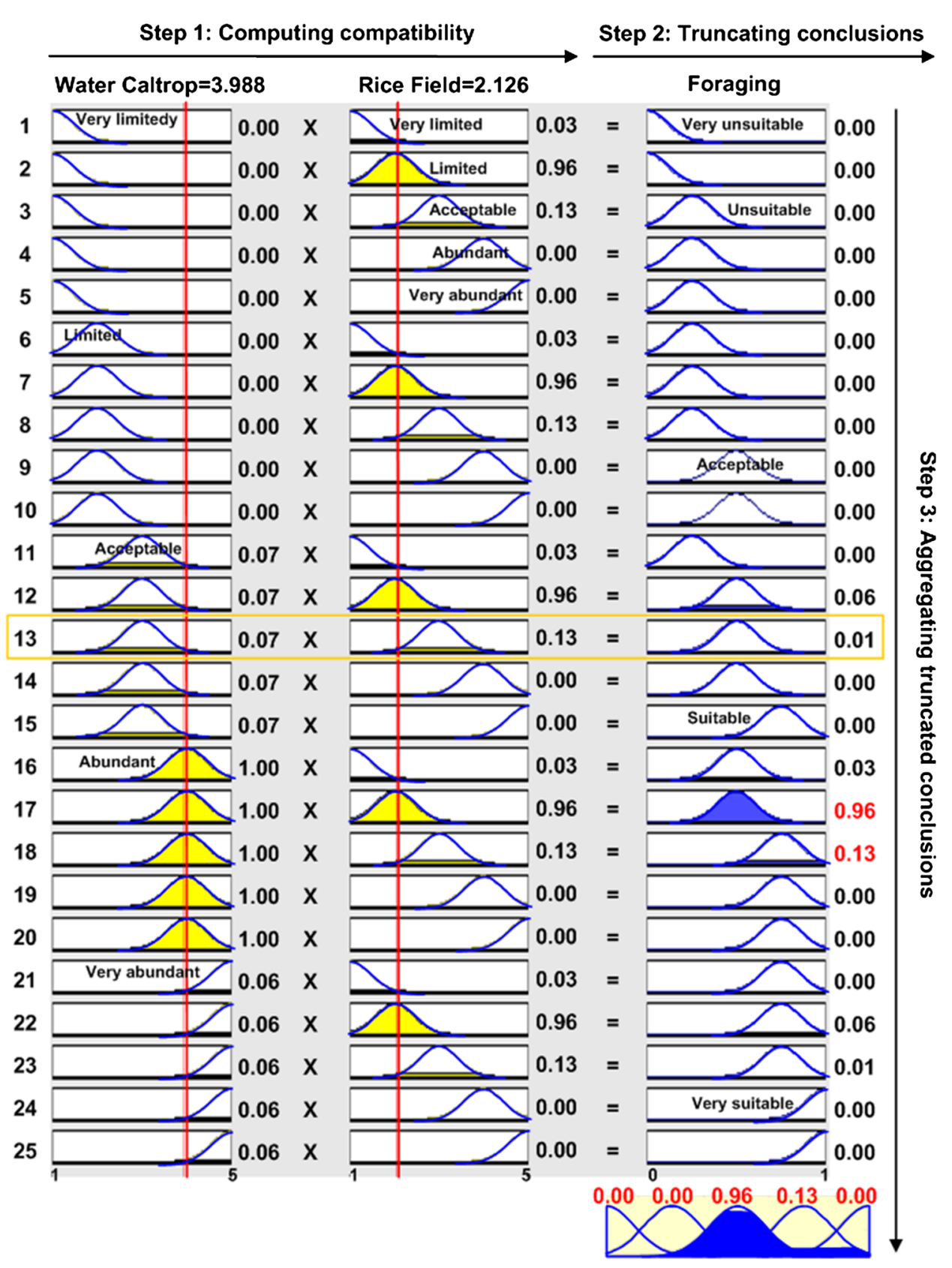

$=0.009$

$\mathrm{P}($ Foraging $=$ unsuitable $\mid$ water caltrop $=$ abundant and rice field $=$ limited)

$=0.01 / 1.12$

$=0.009$

$\mathrm{P}($ Foraging $=$ acceptable $\mathrm{I}$ water caltrop $=$ abundant and rice field $=$ limited)

$=0.96 / 1.12$

$=0.857$

$\mathrm{P}($ Foraging $=$ suitable $\mathrm{I}$ water caltrop $=$ abundant and rice field $=$ limited)

$=0.13 / 1.12$

$=0.116$ 
$\mathrm{P}($ Foraging $=$ very suitable $\mid$ water caltrop $=$ abundant and rice field $=$ limited)

$=0.010 / 1.12$

$=0.009$

\section{Results and discussion}

Model development and evaluation

A widely used software package, Netica (Norsys Software Corp. Canada), was employed to implement the BBN model. Its graphical user interfaces makes it easy for users to build the network structure manually. It offers a mechanism for learning CPs from cases, but this was not used because of the insufficient number of cases. Instead, the fuzzy logic is used to generate the CPs and is implemented with the MATLAB Fuzzy Logic Toolbox.

Sometimes it is useful to know the degree to which a belief in a particular node is influenced by findings at other nodes. Netica computes a node's "sensitivity to findings," using the mutual information. In probability theory and information theory, the mutual information of two random variables is a quantity that measures the mutual dependence of the two random variables. The mutual information determines which variables and states of variables are more influential, with respect to the target variable. It shows when small changes in the probability of a state cause great changes in the probability distribution of the target variable (Aguilera et al. 2011). The information also helps to identify errors in either the network structure or the CPs and provides guidance for the collection of further data or for eliciting direct expert evaluation (Pollino et al. 2007a). For the case study, the result for the sensitivity to findings is shown in Table 5. For the target node (future population status), the suitability of breeding, the suitability of foraging, water caltrop, and the suitability of habitat are the most crucial survival factors. It should also be noted that water caltrop is the most crucial survival factor for the suitability of breeding, foraging, and habitat, simultaneously, because it provides a space for nesting, foraging, and resting.

\section{Scenario testing}

Four scenarios are considered in the EIA report: the $\mathrm{BC}$, the PIWOM, the PIWM, and the prediction of the impact with a RP. For every scenario, the possible states for each survival factor are shown in Table 2, which are evaluated by authors primarily based on the EIA report and other supplemental materials such as reports (Chiu 2004; Ueng 2008), theses (Chen 2008;
Table 5 Sensitivity to a target node due to a finding in its relevant survival factors

\begin{tabular}{lll}
\hline Target node & $\begin{array}{l}\text { Important relevant survival } \\
\text { factor }\end{array}$ & $\begin{array}{l}\text { Mutual } \\
\text { information }\end{array}$ \\
\hline Future population status & Breeding & 0.43275 \\
& Foraging & 0.37896 \\
& Water caltrop & 0.37488 \\
& Habitat & 0.35407 \\
Hibernacula & 0.13050 \\
Embankment & 0.08780 \\
Exterior threat & 0.02639 \\
Mud & 0.01906 \\
Rice field & 0.01315 \\
Foraging & Water quality & 0.00621 \\
Habitat & Swampland & 0.00394 \\
Brushwood and shrubbery & 0.00314 \\
& Water caltrop & 0.31002 \\
& Embankment & 0.08980 \\
Swampland & 0.06019 \\
& Brushwood and shrubbery & 0.04809 \\
& Exterior threat & 0.03705 \\
& Embankment & 0.62838 \\
Mud & 0.28274 \\
& Water caltrop & 0.78097 \\
Rice field & 0.20053 \\
Water caltrop & 0.43615 \\
Exterior threat & 0.17337 \\
Water quality & 0.08253 \\
\hline
\end{tabular}

Deng 2010), and related discussion on the Internet. The detailed information for the four scenarios (Table 2) is the input of the BBN model, and the probability distribution over all possible states for each survival factor is then obtained, as shown in Table 6. For the BC, the most probable suitability of "breeding" is "acceptable," with the highest probability being $90.09 \%$; the most probable suitability of "foraging" is "acceptable," with the highest probability being $86.73 \%$; the most probable suitability of "habitat" is "acceptable," with the highest probability being $88.29 \%$, and the most probable suitability of "hibernacula" is "acceptable," with the highest probability being $90.91 \%$. Ultimately, the most probable status of the future population of the Pheasant-tailed jacanas is "moderate," with the highest probability being $88.56 \%$, as demonstrated in Fig. 3 and shown in the BC column of Table 6. Because of the construction work for the Taiwan High-Speed Railway, the most probable suitability of "breeding," "foraging," "habitat," and "hibernacula" is shifted one level to "unsuitable," "unsuitable," "unsuitable," and "unsuitable," 
Table 6 The derived probability distributions for the survival factors for the four scenarios

\begin{tabular}{|c|c|c|c|c|c|}
\hline Survival factor & State & $\begin{array}{l}\mathrm{BC} \\
(\%)\end{array}$ & $\begin{array}{l}\text { PIWOM } \\
(\%)\end{array}$ & $\begin{array}{l}\text { PIWM } \\
(\%)\end{array}$ & $\begin{array}{l}\mathrm{RP} \\
(\%)\end{array}$ \\
\hline \multirow[t]{5}{*}{ Breeding } & $\begin{array}{l}\text { Very } \\
\text { unsuitable }\end{array}$ & 0.90 & 0.93 & 0.94 & 0.89 \\
\hline & Unsuitable & 0.90 & 87.85 & 86.79 & 0.89 \\
\hline & Acceptable & 90.09 & 9.35 & 10.38 & 5.36 \\
\hline & Suitable & 7.21 & 0.93 & 0.94 & 85.71 \\
\hline & $\begin{array}{l}\text { Very } \\
\text { suitable }\end{array}$ & 0.90 & 0.93 & 0.94 & 7.14 \\
\hline \multirow[t]{5}{*}{ Foraging } & $\begin{array}{l}\text { Very } \\
\text { unsuitable }\end{array}$ & 0.88 & 0.92 & 0.92 & 0.90 \\
\hline & Unsuitable & 4.42 & 88.07 & 88.07 & 0.90 \\
\hline & Acceptable & 86.73 & 9.17 & 9.17 & 0.90 \\
\hline & Suitable & 7.08 & 0.92 & 0.92 & 89.09 \\
\hline & $\begin{array}{l}\text { Very } \\
\text { suitable }\end{array}$ & 0.88 & 0.92 & 0.92 & 8.18 \\
\hline \multirow[t]{5}{*}{ Habitat } & $\begin{array}{l}\text { Very } \\
\text { unsuitable }\end{array}$ & 0.90 & 1.06 & 0.95 & 0.89 \\
\hline & Unsuitable & 0.90 & 94.68 & 4.76 & 0.89 \\
\hline & Acceptable & 88.29 & 2.13 & 92.38 & 0.89 \\
\hline & Suitable & 9.01 & 1.06 & 0.95 & 8.93 \\
\hline & $\begin{array}{l}\text { Very } \\
\text { suitable }\end{array}$ & 0.90 & 1.06 & 0.95 & 88.39 \\
\hline \multirow[t]{5}{*}{ Hibernacula } & $\begin{array}{l}\text { Very } \\
\text { unsuitable }\end{array}$ & 0.90 & 2.63 & 2.63 & 0.90 \\
\hline & Unsuitable & 0.90 & 87.72 & 87.72 & 0.90 \\
\hline & Acceptable & 90.91 & 7.89 & 7.89 & 0.90 \\
\hline & Suitable & 6.36 & 0.88 & 0.88 & 90.09 \\
\hline & $\begin{array}{l}\text { Very } \\
\text { suitable }\end{array}$ & 0.90 & 0.88 & 0.88 & 7.21 \\
\hline \multirow{5}{*}{$\begin{array}{l}\text { Future } \\
\text { population } \\
\text { status }\end{array}$} & Very weak & 0.97 & 1.04 & 0.96 & 0.91 \\
\hline & Weak & 1.26 & 84.01 & 62.53 & 0.91 \\
\hline & Moderate & 88.56 & 12.78 & 34.39 & 2.23 \\
\hline & Strong & 8.24 & 1.12 & 1.15 & 75.49 \\
\hline & Very strong & 0.97 & 1.04 & 0.96 & 20.45 \\
\hline
\end{tabular}

respectively, and the most probable status of the future population of the Pheasant-tailed jacanas is further rated as "weak," with the highest probability being $84.01 \%$, as shown in the PIWON column of Table 6.

If the mitigation measures, as described in the EIA report (section "Materials and methods"), are taken, the analysis shows that only the suitability of habitat is improved from "unsuitable" to "acceptable," because the mitigation measures primarily reduce the disturbance due to construction (exterior threat) and water pollution. The future population of the Pheasant-tailed jacanas is then considered to be a combination of "weak," with a probability of $62.53 \%$, and "moderate," with a probability of
$34.39 \%$, as shown in the PIWN column of Table 6. This result implies that the PIWN is not satisfactory. A useful feature of the BBN is that it can help to manage environmental or ecological risk by testing causes, given the hypothetical effects (Hart and Pollino 2008). Assuming that the EIA committee ask the developer to maintain the suitability of "breeding," "foraging," "hibernacula," and "habitat" as "acceptable," during the construction work, the BBN model suggests that the condition of exterior threat should be improved to the level of "very slight," with a highest probability of $79.84 \%$. This "very slight" exterior threat is very difficult or very costly to achieve, during the construction work, because it is better than the "slight" exterior threat for the BC. Another solution is the $\mathrm{RP}$, as described in section "Materials and methods". The RP largely improves the environmental conditions for the Pheasant-tailed jacanas. For the RP, the most probable suitability of "breeding" is "suitable," with the highest probability being $85.71 \%$; the most probable suitability of "foraging" is "suitable," with the highest probability being $89.09 \%$; the most probable suitability of "habitat" is "very suitable," with the highest probability being $88.39 \%$, and the most probable suitability of "hibernacula" is "suitable," with the highest probability being $90.09 \%$. Ultimately, the most probable status of the future population of the Pheasant-tailed jacanas is "strong," with the highest probability being 75.49 , as shown in the RP column of Table 6 .

\section{Conclusion}

This study proposes a BBN model for ecological assessment in EIA, whose features include the representation of the demonstration of the probabilistic relationships between survival factors and adverse ecological effects, using the graphical structures of the BBN, the construction of stress-response relationships, using the CPs of the BBN, and the capability to predict the population status of a rare animal using the inference mechanism of the BBN. The 19,625 CPs in the BBN model are very difficult to generate, because of the lack of sufficient data concerning rare animals. Therefore, this paper uses fuzzy logic to allow experts to generate these CPs.

In the case study, the status of the future population of the Pheasant-tailed jacana is affected by the construction work for the Taiwan High-Speed Railway. In terms of the $\mathrm{BC}$, the most probable status of the future population is "moderate," with the highest probability being $88.56 \%$, but this is reduced to "weak," with the highest probability 
being $84.01 \%$, in the construction phase. It is slightly improved (a combination of "weak," with a probability of $62.53 \%$, and "moderate," with a probability of $34.39 \%$ ), if the mitigation measures are taken, but the result is not satisfactory. Ultimately, the RP significantly improves the environmental conditions for the Pheasant-tailed jacana, and the most probable status of the future population of the Pheasant-tailed jacana is "strong," with the highest probability being $75.49 \%$.

Acknowledgments The authors would like to thank the National Science Council of the Republic of China (Taiwan) for financially supporting this research under Contract NSC 99-2221-E-131-010MY2. The author also appreciates the editorial assistance provided by Dr. Michael McGarrigle.

\section{References}

Aguilera PA, Fernández A, Fernándeza R, Rumíb R, Salmerónb A (2011) Bayesian networks in environmental modelling. Environ Model Softw 26(12):1376-1388

Baker S, Mendes E (2010) Evaluating the weighted sum algorithm for estimating conditional probabilities in Bayesian networks. In: Proceedings of the Software Engineering and Knowledge Engineering Conference (SEKE 2010): 319-324

Bangian AH, Ataei M, Sayadi A, Gholinejad A (2012) Optimizing post-mining land use for pit area in open-pit mining using fuzzy decision making method. Int J Environ Sci Technol 9(4):613-628

Bashari H, Smith C, Bosch OJH (2008) Developing decision support tools for rangeland management by combining state and transition models and Bayesian belief networks. Agric Syst 99(1):23-34

Borsuk ME, Stow CA, Reckhow KH (2003) Integrated approach to total maximum daily load development for Neuse River Estuary using Bayesian probability network model (Neu-BERN). J Water Resour Plann Manag-ASCE 129(4):271-282

Borsuk ME, Stow CA, Reckhow KH (2004) A Bayesian network of eutrophication models for synthesis, prediction, and uncertainty analysis. Ecol Model 173(2-3):219-239

Borsuk ME, Reichert P, Peter A, Schager E, Burkhardt-Holm P (2006) Assessing the decline of brown trout (Salmo trutta) in Swiss rivers using a Bayesian probability network. Ecol Model 192(1-2):224-244

Chan TU, Hart BT, Kennard MJ, Pusey BJ, Shenton W, Douglas MM, Valentine E, Patel S (2012) Bayesian network models for environmental flow decision making in the Daly River, Northern Territory, Australia. River Res Appl 28(3):283-301

Chen TC (2008) Breeding Biology of Pheasant-tailed jacana Hydrophasianus chirurgus in Taiwan. Doctoral dissertation, National Taiwan University, Taipei

Chiu MX (2004) The habitat management of jacana restoration area. Technical report of the Jacana Restoration Commission

Das B (2004) Generating conditional probabilities for Bayesian networks: easing the knowledge acquisition problem. arxiv.org/ $\mathrm{pdf} / \mathrm{cs} / 0411034 \mathrm{v} 1$. Accessed in 2013

Deng BL (2002) Introduction of jacana. Jacana Restor 75:40-45 (in Chinese)

Deng BL (2010) The habitats management models for the breeding of the Pheasant-tailed jacana in Guan-Tian Jacana Restoration Area, Tainan County, Master's thesis, National Kaohsiung Normal University, Kaohsiung
Dlamini WM (2010) A Bayesian belief network analysis of factors influencing wildfire occurrence in Swaziland. Environ Model Softw 25(2):199-208

Dlamini WM (2011) Bioclimatic modeling of southern African bioregions and biomes using Bayesian networks. Ecosystems 14(3):366-381

Dubois D, Prade H (2010) Formal representations of uncertainty. In: Bouyssou D, Dubois D, Prade H, Pirlot M (eds) Decision making process: concepts and methods. Wiley-ISTE, London

Eleye-Datubo AG, Wall A, Wang J (2008) Marine and offshore safety assessment by incorporative risk modeling in a fuzzy-Bayesian network of an induced mass assignment paradigm. Risk Anal 28(1):95-112

Gibbs MT (2007) Assessing the risk of an aquaculture development on shorebirds using a Bayesian belief model. Hum Ecol Risk Assess 13(1):156-179

Grech A, Coles RG (2010) An ecosystem-scale predictive model of coastal seagrass distribution. Aquat Conserv: Mar Freshw Ecosyst 20(4):437-444

Hamilton GS, Fielding F, Chiffings AW, Hart BT, Johnstone RW, Mengersen KL (2007) Investigating the use of a bayesian network to model the risk of Lyngbya majuscula bloom initiation in deception bay, Queensland. Hum Ecol Risk Assess 13(6): 1271-1287

Hammond TR, Ellis JR (2002) Ameta-assessment for elasmobranchs based on dietary data and Bayesian networks. Ecol Indic 1(3):197-211

Hart BT, Pollino CA (2008) Increased use of Bayesian network models will improve ecological risk assessments. Hum Ecol Risk Assess 14(5):851-853

Helle I, Lecklin T, Jolma A, Kuikka S (2011) Modeling the effectiveness of oil combating from an ecological perspective - a Bayesian network for the Gulf of Finland; the Baltic Sea. J Hazard Mater 185(1):182-192

Howes AL, Maron M, McAlpine CA (2010) Bayesian networks and adaptive management of wildlife habitat. Conserv Biol 24(4):974-983

Johnson S, Mengersen K, de Waal A, Marnewick K, Cilliers D, Houser AM, Boast L (2010) Modelling cheetah relocation success in southern Africa using an iterative Bayesian network development cycle. Ecol Model 221(4):641-651

Kao HY, Huang CH, Hsu CL, Huang CL (2011) Diagnosis from Bayesian networks with fuzzy parameters-a case in supply chains. J Internet Technol 12(1):49-55

Karimi AR, Mehrdadi N, Hashemian SJ, Nabi Bidhendi GR, Tavakkoli Moghaddam R (2011) Selection of wastewater treatment process based on the analytical hierarchy process and fuzzy analytical hierarchy process methods. Int $\mathbf{J}$ Environ Sci Technol 8(2):267-280

Li HL, Kao HY (2005) Constrained abductive reasoning with fuzzy parameters in Bayesian networks. Comput Oper Res 32(1):87-105

Li PC, Chen GH, Dai LC, Zhang L (2012) A fuzzy Bayesian network approach to improve the quantification of organizational influences in HRA frameworks. Saf Sci 50(7):1569-1583

Liu KFR, Lai JH (2009) Decision support for environmental impact assessment: a hybrid approach using fuzzy logic and fuzzy analytic network process. Expert Sys Appl 36(3):5119-5136

Liu KFR, Lu CF, Chen CW, Shen YS (2012) Applying Bayesian belief networks to health risk assessment. Stoch Environ Res Risk Assess 26(3):451-465

Liu KFR, Chen CW, Shen YS (2013) Using Bayesian belief networks to support health risk assessment for sewer workers. Int $\mathrm{J}$ Environ Sci Technol 10(2):385-394

Mandal SN, Choudhury JP, Bhadra Chaudhuri SR (2012) In search of suitable fuzzy membership function in prediction of time series data. Int J Comput Sci 9(3):293-302 
Marcot BG, Holthausen RS, Raphael MG, Rowland MM, Wisdom MJ (2001) Using Bayesian belief networks to evaluate fish and wildlife population viability under land management alternatives from an environmental impact statement. Ecology Manag 153(1-3):29-42

Marcot BG, Hohenlohe PA, Morey S, Holmes R, Molina R, Turley MC, Huff MH, Laurence JA (2006) Characterizing species at risk II: using Bayesian belief networks as decision support tools to determine species conservation categories under the northwest forest plan. Ecol Soc 11(2):12

Martin TG, Burgman MA, Fidler F, Kuhnert PM, Low-Choy S, Mcbride M, Mengersen K (2012) Eliciting expert knowledge in conservation science. Conserv Biol 26(1):29-38

McNay RS, Marcot BG, Brumovsky V, Ellis R (2006) A Bayesian approach to evaluating habitat for woodland caribou in northcentral British Columbia. Can J For Res 36(12):3117-3133

Newton AC (2010) Use of a Bayesian network for red listing under uncertainty. Environ Model Softw 25(1):15-23

Nicholson AE, Flores MJ (2011) Combining state and transition models with dynamic Bayesian networks. Ecol Model 222(3):555-566

Nyberg JB, Marcot BG, Sulyma R (2006) Using Bayesian belief networks in adaptive management. Canadian $\mathrm{J}$ For Res 36(12):3104-3116

Oteniya L (2008) Bayesian belief networks for dementia diagnosis and other applications: a comparison of hand-crafting and construction using a novel data driven technique, $\mathrm{PhD}$ thesis of University of Stirling, Scotland. https://dspace.stir.ac.uk/handle/ $1893 / 497$

Pearl J (1988) Probabilistic reasoning in intelligent systems: networks of plausible inference. Morgan Kaufmann, California

Penz CA, Flesch CA, Nassar SM, Flesch RCC, de Oliveira MA (2012) Fuzzy-Bayesian network for refrigeration compressor performance prediction and test time reduction. Expert Sys Appl 39(4):4268-4273

Petts J (1999) Handbook of environmental impact assessment volume 2: environmental impact assessment in practice: impact and limitations. Blackwell Science, Oxford

Pollino CA, White AK, Hart BT (2007a) Examination of conflicts and improved strategies for the management of an endangered Eucalypt species using Bayesian networks. Ecol Model 201(1):37-59

Pollino CA, Woodberry O, Nicholson A, Korb K, Hart BT (2007b) Parameterisation and evaluation of a Bayesian network for use in an ecological risk assessment. Environ Model Softw 22(8):1140-1152

Radliński Ł (2013) An expert-driven Bayesian network model for simulating and predicting software quality. In: Proceedings Fifth International Conference on information, process, and knowledge management, Nice, France, 26-31

Raphael MG, Wisdom MJ, Rowland MM, Holthausen RS, Wales BC, Marcot BG, Rich TD (2001) Status and trends of habitats of terrestrial vertebrates in relation to land management in the interior Columbia River Basin. For Ecol Manag 153(1):63-87

Ren J, Jenkinson I, Wang J, Xu DL, Yang JB (2009) An offshore risk analysis method using fuzzy Bayesian network. J Offshore Mech Arct Eng-Trans ASME 131:041101

Renken H, Mumby PJ (2009) Modelling the dynamics of coral reef macroalgae using a Bayesian belief network approach. Ecol Model 220(9-10):1305-1314

Rieman B, Peterson JT, Clayton J, Howell P, Thurow R, Thompson W, Lee D (2001) Evaluation of potential effects of federal land management alternatives on trends of salmonids and their habitats in the interior Columbia River basin. For Ecol Manag 153(1):43-62

Sadoddin A, Letcher RA, Jakeman AJ, Newhamb LTH (2005) A Bayesian decision network approach for assessing the ecological impacts of salinity management. Math Comput Simul 69(1-2):162-176

Shenton W, Hart BT, Brodie J (2010) A Bayesian network model linking nutrient management actions in the Tully catchment (northern Queensland) with Great Barrier Reef condition. Mar Freshw Res 61(5):587-595

Shenton W, Hart BT, Chan T (2011) Bayesian network models for environmental flow decision-making: 1. Latrobe River Australia. River Res Appl 27(3):283-296

Smith CS, Howes AL, Price B, McAlpine CA (2007) Using a Bayesian belief network to predict suitable habitat of an endangered mammal-the Julia Creek dunnart (Sminthopsis douglasi). Biol Conserv 139(3-4):333-347

Steventon JD, Sutherland GD, Arcese P (2006) A populationviability-based risk assessment of Marbled Murrelet nesting habitat policy in British Columbia. Canadian $\mathbf{J}$ For Res 36(12):3075-3086

Tuzkaya G (2013) An intuitionistic fuzzy Choquet integral operator based methodology for environmental criteria integrated supplier evaluation process. Int J Environ Sci Technol. doi:10.1007/ s13762-013-0180-9

Tuzkaya G, Gulsun B (2008) Evaluating centralized return centers in a reverse logistics network: an integrated fuzzy multi-criteria decision approach. Int J Environ Sci Technol 5(3):339-352

Tuzkaya G, Ozgen A, Ozgen D, Tuzkaya UR (2009) Environmental performance evaluation of suppliers: a hybrid fuzzy multicriteria decision approach. Int J Environ Sci Technol 6(3): $477-490$

Ueng YT (2008) Analysis of jacanas conservation plan in Tainan County. Technical report of Taiwan Forestry Bureau

Uusitalo L (2007) Advantages and challenges of Bayesian networks in environmental modeling. Ecol Model 203(3-4):312-318

Uusitalo L, Kuikka S, Romakkaniemi A (2005) Estimation of Atlantic salmon smolt carrying capacity of rivers using expert knowledge. ICES J Mar Sci 62(4):708-722

Vilizzi L, Price A, Beesley L, Gawne B, King AJ, Koehn JD, Meredith DL, Nielsen CP, Sharpe CP (2012) The belief index: an empirical measure for evaluating outcomes in Bayesian belief network modelling. Ecol Model 228:123-129

Walton A, Meidinger D (2006) Capturing expert knowledge for ecosystem mapping using Bayesian networks. Canadian J For Res 36(12):3087-3103

Wang Y, Xie M (2012) Approach to integrate fuzzy fault tree with Bayesian network. Procedia Eng 45:131-138

Wang Y, Xie M, Ming K, Meng YF (2011) Quantitative risk analysis model of integrating fuzzy fault tree with bayesian network. In: IEEE international conference on intelligence and security informatics (ISI): 267-271

Wilson DS, Stoddard MA, Puettmann KJ (2008) Monitoring amphibian populations with incomplete survey information using a Bayesian probabilistic model. Ecol Model 214(2-4): 210-218

Wooldridge S, Done T (2004) Learning to predict large-scale coral bleaching from past events: a Bayesian approach using remotely sensed data, in situ data, and environmental proxies. Coral Reefs 23(1):96-108

Young WA, Millie DF, Weckman GR, Anderson JS, Klarer DM, Fahnenstiel GL (2011) Modeling net ecosystem metabolism with an artificial neural network and Bayesian belief network. Environ Model Softw 26(10):1199-1210 
Zadeh LA (1975) The concept of a linguistic variable and its application to approximate reasoning-I. Inf Sci 8:199-249

Zadeh LA (1996) Fuzzy logic= computing with words. IEEE Trans Fuzzy Syst 4(2):103-111
Zadeh LA (2002) From computing with numbers to computing with words. From manipulation of measurements to manipulation of perceptions. Int J Appl Math Comput Sci 12(3):307-324 